Estructura económica de las Cooperativas De Ahorro y Crédito en Venezuela http://doi.org/10.33996/revistaenfoques.v1i2.8 No. 2 | Volumen 1 | Abril - Junio 2017 http://revistaenfoques.org ISSN: $2616-8219$

\section{ESTRUCTURA ECONÓMICA DE LAS COOPERATIVAS DE AHORRO Y CRÉDITO EN VENEZUELA}

\author{
THE ECONOMIC STRUCTURE IN THE VENEZUELAN SAVINGS \\ AND CREDIT COOPERATIVES
}

\author{
Carmen Thais Figueredo
}

\section{Resumen}

El presente artículo tiene como propósito describir la estructura económica en las cooperativas venezolanas de ahorro y crédito inscritas en la Central de Integración Cooperativa de la Región Capital a partir de las Normas Internacionales de Información Financiera completas y las Normas de contabilidad de la Superintendencia Nacional de Cooperativas. Fue una investigación descriptiva bajo el diseño documental y de campo, la población la conforman las cooperativas de ahorro y crédito. Los resultados indican que las cooperativas en el reconocimiento del elemento de la estructura económica-financiera no evalúan si la partida cumple la definición de elemento. Determinan la medición inicial de los elementos en función del monto pagado en efectivo o de la factura. El reconocimiento de la partida lo realizan según las especificaciones de la factura registrándolo en activo, pasivo, costos, gastos en la estructura del código contable. Las cooperativas no cuentan con un marco conceptual que les indique los conceptos necesarios para la preparación y presentación de los estados financieros para usuarios externos.

Palabras clave: Contabilidad; NIIF completas; Normas SUNACOOP; Sociedades Cooperativas; Valoración de la estructura económico-financiera

\begin{abstract}
The purpose of this article is to describe the economic structure of Venezuelan credit unions registered in the Central of Cooperative Integration of the Capital Region based on the complete International Financial Reporting Standards and the Accounting Standards of the National Superintendence of Cooperatives. It was a descriptive investigation under the documentary and field design, the population is made up of credit unions. The results indicate that cooperatives in recognizing the element of the economic-financial structure do not assess whether the item meets the definition of the element. They determine the initial measurement of the elements based on the amount paid in cash or the invoice. The recognition of the item is made according to the specifications of the invoice by registering it in assets, liabilities, costs, expenses in the structure of the accounting code. Cooperatives do not have a conceptual framework that indicates the concepts necessary for the preparation and presentation of financial statements for external users.
\end{abstract}

Key words: Accounting; complete IFRS; SUNACOOP Standards; Cooperative

\section{Carmen Thais Figueredo}

thaisfigueredo22@yahoo.es

Universidad de los Andes, Venezuela

Doctora en Ciencias Contables, Universidad de Los Andes julio 2015. Magister Scientiarum en Ciencias Administrativas, Universidad Central de Venezuela, diciembre 1996. Especialista en Ciencias Administrativas Mención Finanzas Universidad Central de Venezuela, noviembre 1993. Licenciada en Contaduría Pública Universidad Central de Venezuela marzo 1978. 


\section{INTRODUCCIÓN}

En la Venezuela actual, el entorno normativo contable está caracterizado por la armonización internacional para todo tipo de organización. Las cooperativas son organizaciones de marcado carácter social, son asociaciones económicas sociales de consumidores o productores que unen su esfuerzo para su mutuo beneficio y para el beneficio de los demás. Se basan en los principios cooperativos, de los cuales, el principio de asociación abierta y voluntaria, marca una de las características que distingue a las cooperativas de las sociedades con fines de lucro como lo es la variabilidad del capital social. De igual manera, el principio de la participación económica igualitaria de los socios destaca la necesidad de satisfacer sus necesidades, y el resultado derivado de las operaciones con los socios es el excedente, repartible entre ellos una vez deducido las partidas obligatorias por ley.

Desde este punto de vista, las cooperativas están llamadas a analizar su régimen económico para establecer las áreas más relevantes afectadas por la adopción de las Normas Internacionales de Información Financiera (NIIF) completas, así como las incidencias de los sistemas de reconocimiento establecidos en estas normas sobre la valoración de la estructura económicofinanciera, específicamente en el tratamiento del capital social, la naturaleza contable del reparto del excedente de los socios, la formulación de los estados financieros consolidados en los grupos cooperativos, y los efectos en los elementos de la estructura económica.

De esta manera se plantea en este artículo conocer la estructura económica de las cooperativas venezolanas de ahorro y crédito inscritas en la Central de Integración Cooperativa de la Región Capital
(CECODIFEMI); para lo cual se hace necesario conocer un poco de su devenir en el tiempo.

En razón de lo antes dicho, se considera de gran importancia que las pequeñas empresas en sintonía con el moderno paradigma del desarrollo local sustentable, actúen en intima vinculación con las universidades, debido al rol de principal organización creadora de conocimiento, así como con otros centros de innovación tecnológica, para asumir en conjunto un compromiso más protagónico en la construcción de las bases para la reducción progresiva de los índices de pobreza del país, mayor independencia económica, eleve el grado de industrialización, y sobre todo, mejore la calidad de vida de los venezolanos.

Estas organizaciones de economía social, en muchos países han desempeñado un papel predominante en el planeamiento e impulso de la responsabilidad social. Deciden voluntariamente contribuir al logro de una sociedad mejor y un medio ambiente más limpio. Se basan en la idea de que el funcionamiento general de una empresa debe evaluarse teniendo en cuenta su contribución combinada con la prosperidad económica, la calidad del medio ambiente y el bienestar de la sociedad en la que se integra. Su objetivo es lograr la excelencia en la empresa, con énfasis en las personas y sus condiciones de trabajo, así como en la calidad de sus procesos productivos con la incorporación de las tres facetas del desarrollo sostenible: la económica, la social y la medioambiental, lo cual favorece la consolidación de la organización, promueve su éxito económico y afianza su proyección de futuro (Fernández, 2009).

Para Valero y León (2009) la responsabilidad social aporta alternativas y argumentos que pueden desarrollar las empresas para favorecer al ser humano, sus 
comunidades y el entorno natural donde se desenvuelven. Para este fin, la responsabilidad social divide su atención en dos dimensiones: la dimensión interna, referida a la gestión del recurso humano, la salud y la seguridad de los puestos de trabajo, así como, la gestión del impacto ambiental y de los recursos naturales; y la dimensión externa representada por las comunidades locales, los derechos humanos, los problemas ecológicos y el desarrollo sostenible.

En el caso particular de las cooperativas, estas organizaciones pueden constituir un factor clave para el desarrollo económico de una región, para tal fin, deben desenvolverse en nuevos entornos cambiantes $y$ competitivos con la finalidad de dinamizar el sector cooperativo en su conjunto, para lograr que sea altamente eficiente, y pueda aprovechar las fortalezas de su estructura y las particularidades de su filosofía.

Las cooperativas son empresas donde sus asociados contribuyen equitativamente al capital y lo controlan democráticamente; por ello, la empresa cooperativa se encuentra hoy ante un reto vital, del cual depende su propia existencia: lograr ser competitivas como organizaciones en un contexto caracterizado por una globalización creciente; además deben hacerlo sin perder sus peculiaridades, con una identidad fuerte y adecuada para las transformaciones de la sociedad y del mercado.

Sobre el cooperativismo en Venezuela se debe señalar enfáticamente, que este movimiento se viene construyendo de manera sostenida a lo largo de los últimos cuarenta y dos años por sectores de la población que creen en las cooperativas como fórmula para enfrentar problemas comunes con sus propios esfuerzos.

Sin embargo, las cooperativas, al igual que otras organizaciones sufren las alteraciones propias de un país con crisis desde los años ochenta, con los peores indicadores sociales y económicos de su historia, y con la incertidumbre sobre las consecuencias del clima político nacional. Bastidas (2003) clasifica este cooperativismo como tradicional, y considera que ha desarrollado importantes experiencias locales con cierta proyección nacional, por lo cual constituye una referencia para variados sectores del país. Este cooperativismo se encontró en su camino con el nacimiento de otro cooperativismo considerado como emergente o también llamado "nuevo cooperativismo", a partir de las políticas surgidas desde el 2000. Para este autor ese nuevo cooperativismo ha mostrado serias deficiencias desde sus inicios, puesto que en muchos casos no ha logrado consolidarse ni desarrollar una actividad económica verdaderamente productiva y social. A pesar de ello Bastidas (2003) considera que, si se lograra superar las debilidades, y se incorporaran las fortalezas del cooperativismo tradicional, se mejoraría el desarrollo, local, regional y nacional.

Un sector particularmente importante para las cooperativas es el sector de ahorro y crédito. Este sector tiene como misión contribuir en la estimulación del desarrollo endógeno y social del país, fortalecer la superación de la pobreza y la tasa de desocupación a través del fomento del ahorro y crédito como un modelo de cultura en cada una de las comunidades donde se hace vida económica, y atender las necesidades y exigencias del mercado para mejorar la condición económica mediante estrategias financieras en beneficio de los asociados y de la comunidad en general. En el panorama cooperativo este sector se distingue por su disposición para apoyar otras experiencias y procesos cooperativos y comunitarios, con lo cual se configura en un instrumento idóneo de desarrollo sostenible. 
En Venezuela, el cooperativismo de ahorro y crédito también posee experiencia en importantes impactos locales. Aquí se destaca la Red de Soluciones Financieras Cooperativas de Cecofal, impulsada por la Central Cooperativa de Falcón (Cecofal), quien afilia 30.000 asociados (aproximadamente el $50 \%$ de la población de la Península de Paraguaná), mediante un sistema integrado de 10 cooperativas entre las que se encuentra la Cooperativa de San José Obrero, ubicada en Punto Fijo que aporta 18.000 asociados, y recaba un promedio de 16 millardos de bolívares anuales en ahorro con operaciones crediticias por montos muy superiores. También se puede mencionar a la Cooperativa Financiera Fincoop, la cual ha logrado establecer una red de cooperativas de ahorro y crédito en varias poblaciones del país gracias a una plataforma computarizada que integra sus servicios (Bastidas, 2004).

Ahora bien, tanto en las cooperativas en general, como en las empresas con fines de lucro, la base de funcionamiento está constituida por la estructura económicofinanciera. Desde la base de funcionamiento se puede tener una visión económica y financiera de la empresa; la estructura económica corresponde a la composición cualitativa de los bienes económicos y la estructura financiera se refiere a la composición cualitativa de las fuentes de financiamiento (Fernández, 1977).

La estructura económica se encuentra formada por todos aquellos elementos y factores que interrelacionados de manera dinámica forman un conjunto relativamente permanente en el tiempo y en el espacio, representados por los bienes y derechos de la organización. Ella constituye la base de desarrollo de la misma.
En toda organización existe una serie de componentes indispensables que atienden a su objetivo general. La estructura económica agrupa los materiales que se procesan y combinan para producir el servicio, la información o el producto final. En función de que estos componentes sean utilizados con máxima eficiencia la empresa debe trabajar en la realización de la actividad productiva y ejecutarla en el menor tiempo posible, con un mínimo esfuerzo y al más bajo costo.

Dentro de los componentes de la estructura económica se encuentran las inversiones duraderas de la empresa las cuales determinan la capacidad o dimensión productiva, y esta dimensión está en función de la demanda a atender, es decir, la capacidad de absorción del mercado. También incluye las inversiones a corto plazo.

La importancia de la estructura económica de la empresa, se establece en el hecho de que permitirá establecer la cantidad necesaria de inversiones a corto plazo para mantener la capacidad productiva requerida.

Actualmente en Venezuela, el órgano rector de la profesión contable es la Federación de Colegios de Contadores Públicos de la República Bolivariana de Venezuela (FCCPRBV), la cual aprobó la adopción, como Principios de Contabilidad de Aceptación General de Venezuela (VENNIF) las Normas Internacionales de Información Financiera (NIIF) emitidas por el Consejo de Normas Internacionales de Contabilidad (IASB), previa revisión de cada una de ellas y del cumplimiento del proceso de auscultación, como lo es la consulta pública. 
Por otra parte, el artículo 53 de la Ley Especial de Asociaciones Cooperativas (LEAC) establece el uso obligatorio de la contabilidad y la presentación de los estados financieros de las cooperativas acorde con los principios de contabilidad de aceptación general, es decir con las NIIF, tal como lo determinó la Federación de Colegios de Contadores Públicos de la República Bolivariana de Venezuela (FCCPRBV).

Sin embargo, por sus características particulares, las cooperativas en Venezuela se rigen además por una norma nacional: la norma de contabilidad de la Superintendencia Nacional de Cooperativas (SUNACOOP), esta norma legislativa es de aplicación obligatoria. En este sentido, la LEAC faculta a SUNACCOP para establecer los mecanismos de rendición de cuenta de estas organizaciones.

El hecho de que las Normas Internacionales de Información Financiera estén diseñadas para todas las entidades con fines de lucro y para todo tipo de empresas, plantea una reflexión sobre la incidencia de estas normas internacionales en la valoración de la estructura económicofinanciera de las sociedades cooperativas, en función de los principios cooperativos.

Algunos de los principios de las cooperativas que se ven afectados por la adopción de las NIIF en la valoración de su estructura económico financiera, son el primer principio (asociación voluntaria y abierta), y el tercer principio (participación económica de los socios).

Estos principios se interpretan así: Los individuos se ponen de acuerdo para agruparse y crear la cooperativa de manera tal, que su aporte inicial es equitativo y administrado democráticamente, con la condición de ser reembolsable. En cambio, en la empresa capitalista la asociación depende de un aporte de capital previamente establecido por los potenciales socios; este aporte condiciona la participación en la utilidad de la empresa y no establece la cláusula de reembolsable.

De acuerdo a las NIIF, si un aporte a la organización es reembolsable se convierte en pasivo exigible (en una deuda). Con esta condición, al aplicar estas normas en las Cooperativas, su patrimonio se vería significativamente reducido. Este planteamiento origina una de las preocupaciones en la aplicación de las NIIF a las cooperativas, en el sentido de sí el capital social debe ser clasificado como fondo propio o como pasivo exigible.

Asimismo, otra preocupación existente tiene que ver con la naturaleza contable del reparto del excedente a los socios clasificados en la contabilidad como retornos, en el sentido de sí, los retornos tienen la consideración de gasto, o, por el contrario, la consideración de distribución del resultado, lo cual forma parte de la estructura financiera. Esta misma consideración se hace con los intereses de las aportaciones de capital.

El supuesto $\mathrm{o}$ inquietud de la investigación conduce a resolver la siguiente interrogante:

¿Cómo es la estructura económicofinanciera de las cooperativas venezolanas de ahorro y crédito inscritas en la Central de Integración Cooperativa de la Región Capital (CECODIFEMI)?

Actualmente dentro de las sociedades mercantiles especiales se ubican las cooperativas como empresas de economía social, consideradas por Fernández, y otros (ob. cit.) como empresas de propiedad colectiva. Sandoval (2013), define las cooperativas como asociaciones que, de conformidad con el principio de ayuda mutua, tienen como objetivo mejorar las 
mutua, tienen como objetivo mejorar las condiciones de vida de sus socios, quienes tienen igualdad de derechos y obligaciones, y sólo responden hasta el monto de sus aportes.

En este contexto, las cooperativas aparecen vinculadas históricamente a la economía social, y constituyen su eje vertebral. Las cooperativas surgen como una iniciativa para socializar la propiedad de la producción, mediante la valoración del trabajo como factor primordial por encima del capital. En sus inicios nace en forma espontánea, sin vinculaciones ideológicas, con el único objetivo de defender los intereses de los trabajadores.

Esto evidencia que el movimiento cooperativo ha sido de larga data. Coopecas (2008) sitúa su origen en la época de la revolución industrial, en Europa durante los años 1750 a 1850. Para ese momento muchos trabajadores recibían su salario en especie de mala calidad, mal tasada y a precios muy altos, en lugar de recibir dinero. Esto mantenía a los trabajadores sometidos a los tenderos que por concederles crédito exigían un mayor valor por la mercancía. Esta situación llevó a los trabajadores a unirse para convertirse en sus propios proveedores, con lo cual surgió la idea de las cooperativas de consumo.

En síntesis, las cooperativas a diferencia de las compañías anónimas, son sociedades de personas, no de capitales. Se fundamentan en la igualdad de derechos de sus integrantes en función a la gestión social. Además, las cooperativas reparten sus excedentes en función de la actividad realizada por sus asociados en el logro del propósito común. En cambio, en la empresa mercantil se distribuye sus excedentes entre los socios de manera proporcional al capital económico que cada uno aportó (SUNACOOP, s. f.)

\section{MÉTODO}

Para recoger la información se utilizó la técnica de la entrevista con una guía de entrevista la cual fue categorizada y analizada utilizando el programa ATLASTi. EI estudio corresponde a una investigación descriptiva, según la fuente de información en el diseño se combina lo documental con el trabajo de campo, ya que la información se obtuvo de fuentes vivas (los administradores de las cooperativas), y de documentos (los registros contables de las cooperativas, los instrumentos normativos NIIF y las Normas SUNACOOP). Según la temporalidad corresponde a un diseño transeccional.

En esta investigación las unidades de estudio son:

Las Cooperativas venezolanas de ahorro y crédito inscritas en CECODIFEMI. Debido a que constituían un número pequeño, no se hizo muestreo, sino que se estudiaron todas las pertenecientes al contexto de estudio la región central de Venezuela. Las fuentes de donde se obtuvo la información fueron los administradores de las cooperativas, quienes actuaron como informantes claves. Así mismo, para triangular la información relacionada con la estructura económicofinanciera de las cooperativas, también se tomaron como fuentes los documentos contables. Se constató la información contenida en el Balance General para las cuentas de activo, pasivo, patrimonio y valoración del activo, el cual reflejó la situación económica social- contable de las cooperativas a una fecha determinada. 
Para el análisis de las normas, las unidades de estudio fueron los documentos que contenían las NIIF y las Normas SUNACOOP, donde había contenidos relacionados con la valoración de la estructura económica financiera.

\section{RESULTADOS Y DISCUSIÓN}

La descripción de la estructura económica de las cooperativas venezolanas de ahorro y crédito inscritas en la Central de Integración Cooperativa de la Región Capital (CECODIFEMI), permitió obtener un diagnóstico de las características de la estructura económico-financiera de las cooperativas seleccionadas, con las particularidades que las distinguen. Con esta finalidad, se procedió en primer lugar a describir la medición inicial de la estructura económica y todos los componentes, como se explica seguidamente.

La estructura económica de las cooperativas inscritas en CECODIFEMI, está integrada por los aportes efectuados por los asociados destinados a la compra de bienes tangibles, intangibles y otras clasificaciones con el objetivo de incorporarlos al proceso productivo.

En el gráfico 1 se muestra la medición inicial de los componentes de la estructura económica. Se inicia con el capital de trabajo, el cual facilita la adquisición de los elementos que están incorporados al desarrollo de la actividad productiva de las cooperativas de ahorro y crédito. Los elementos que contribuyen al desarrollo de la actividad productiva en estas cooperativas están clasificados y señalados en el gráfico como: Activos intangibles, propiedades, planta y equipo, pre-pagados, cargos diferidos y otros activos.

Con estos elementos de activos, las cooperativas desarrollan su proceso productivo, como es el financiamiento otorgado a los asociados, estos desembolsos se registran en las cuentas por cobrar. A medida que los asociados cancelan sus acreencias las cooperativas cuentan con la disponibilidad en efectivo o bancos, y de acuerdo a su proyección, parte de estos recursos son invertidos en la adquisición de inversiones en instrumentos financieros y en inmuebles.

En forma genérica se menciona la clasificación de las inversiones en valores en las cooperativas. La clasificación atiende a las disposiciones de la Declaración de Principios de Contabilidad (DPC N 15), en: Inversiones temporales donde se agrupan las inversiones negociables, disponibles para la venta y conservadas hasta su vencimiento cuando éste ocurre en el próximo ejercicio económico.

La otra clasificación corresponde a las inversiones permanentes, donde se agrupan las inversiones conservadas hasta el vencimiento, en esta categoría priva la intención de la cooperativa en mantenerla hasta el vencimiento como es el caso de los bonos, y las inversiones en títulos de patrimonio como son las acciones, conocidos como certificados de aportación en las cooperativas. Las inversiones en inmuebles corresponden a terrenos e inmuebles con fines especulativos.

Seguidamente se desarrolla en forma más específica la medición y valoración de los elementos que forman parte de la estructura económica. 


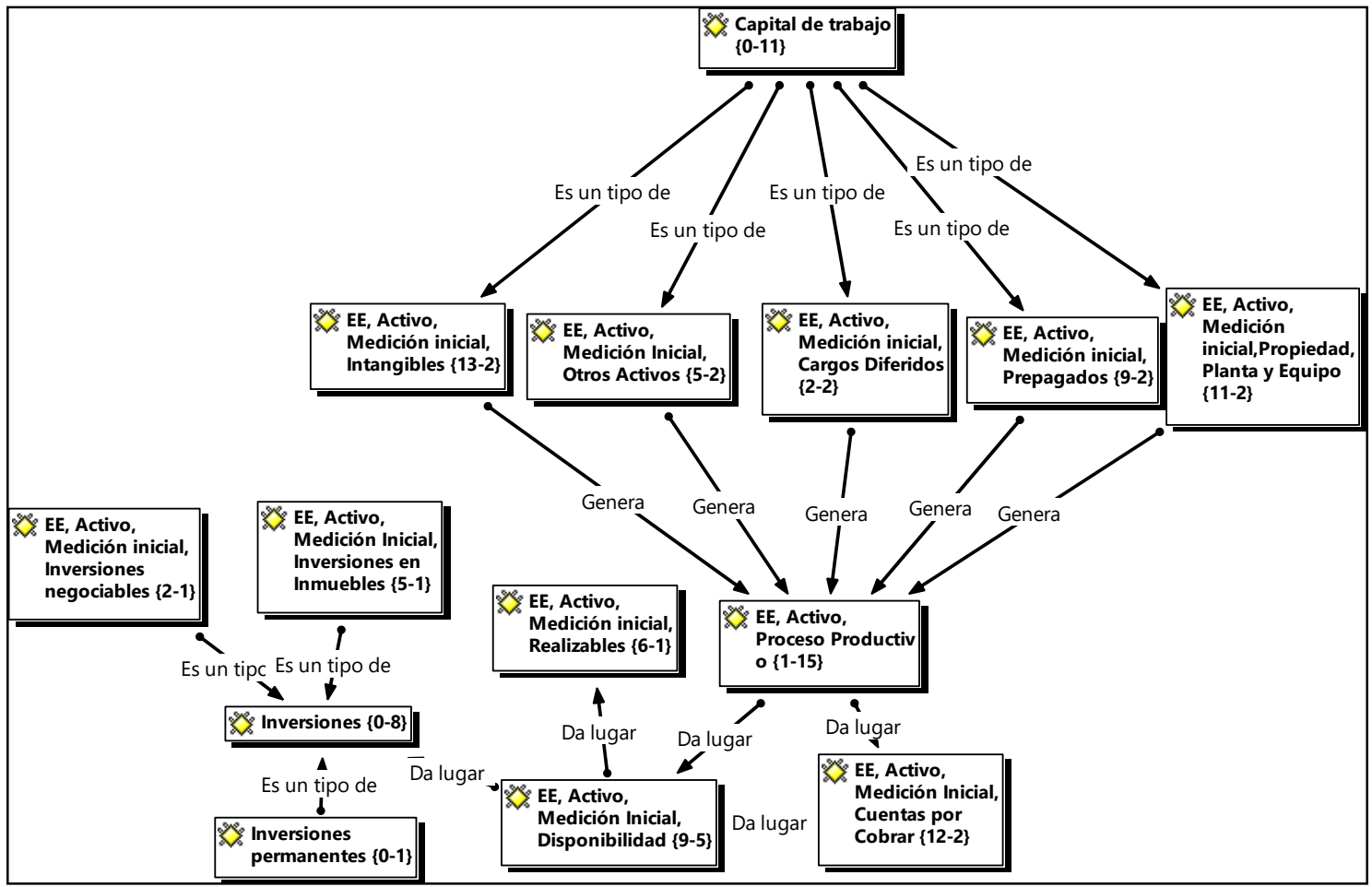

Gráfico 1. Red general de la medición inicial en la estructura económica de las cooperativas.

Otro de los elementos de la estructura económica de las cooperativas es el capital de trabajo. Los recursos financieros son recibidos por las cooperativas mediante los certificados de aportación y asociación de los cooperativistas. Estos recursos permiten la adquisición de elementos de propiedades, planta y equipo, bienes intangibles, cargos diferidos, pre-pagados y otros activos, con los cuales las cooperativas desarrollan su actividad económica. Los elementos para ser incorporados al balance de situación en determinado período, deben ser medidos aplicando los principios de contabilidad generalmente aceptados vinculados al bien específico y contenidos en las disposiciones normativas nacionales en primer lugar, y en segundo lugar y de manera supletoria por las normas internacionales.

La medición inicial de los elementos de estos activos las cooperativas la realizan en función del principio contable de valor histórico original. Según la DPC 0 (20052007) son las transacciones y eventos económicos que la contabilidad cuantifica se registran según las cantidades de efectivo que se afecten o su equivalente o la estimación razonable que de ellos se haga al momento en que se consideren realizados contablemente. El concepto es bastante claro, el costo representa el precio de intercambio pactado y convenido entre el comprador y vendedor. Aclara la DPC 0 (2005-2007) que estas cifras deberán ser modificadas en el caso de ocurrir eventos posteriores que las hagan perder su significado, aplicando los métodos de ajustes aceptados por los principios de contabilidad que en forma sistemática preserven la equidad y la objetividad de la información contable. 
El valor histórico original es una base para la cuantificación y medición de las transacciones y operaciones 0 eventos económicos, el cual pierde su vigencia en economías con alta inflación y por lo tanto, se deben modificar las cifras para ajustar por alguno de los métodos de valoración que establecen las normas. Aun cuando el valor histórico original es en principio la primera manera de cuantificar y registrar las operaciones, esta unidad de medida se ve alterada por la pérdida del poder adquisitivo de la moneda (Catacora, 1999).

Expone Catacora que la DPC 0 habla de valor histórico original y no de costo histórico, por cuanto el término valor es mucho más amplio que el de costo y como toda definición doctrinaria, debe abarcar el universo aplicable de casos, en este sentido, el término valor abarca al menos los siguientes conceptos: (a) costo o valor histórico original, (b) costo o valor de reposición, (c) valor neto de realización, (d) valor de uso, (f) valor de desecho, (g) valor de avalúo. Sigue explicando el autor que se utiliza valor que es más amplio que el término costo específicamente en sentido económico, sin embargo en este caso, es más fácil asociarlo con precio.

Cuando se habla de valor histórico original, comúnmente se acostumbra a expresarlo en términos de precio de costo, costos históricos o sencillamente costo. EI costo es el precio de intercambio de los bienes y servicios en la fecha de su adquisición.

En el gráfico 2 se expone la medición inicial de cada elemento que integra la estructura económica de las cooperativas. Su descripción se señala seguidamente. EI procedimiento de medición debe estar asociado al cumplimiento de la definición de cada elemento con la finalidad de evaluar si el costo puede ser medido con confiabilidad y de que este elemento incorpore cualquier beneficio económico en el sentido de que la partida entre o salga de la cooperativa. Las cooperativas no asocian la medición con la definición del elemento a incorporar en los estados financieros, sólo se limitan a transcribir el código contable de la transacción en función de lo especificado en la factura. En este sentido, se transcriben algunas de las entrevistas realizadas a las cooperativas.

CAsocontasul: Por ejemplo, cuando se compró la computadora, la factura se anexa a una carpeta con las especificaciones de la compra de ese artículo, se le entrega a la Contable y ella lo registra en el código correspondiente, según normas de SUNACOOP.

CCohello: Las transacciones en activo, ingreso, gasto, pasivo se registran por medio de la factura según el código contable de SUNACOOP, procurando que el ingreso registrado sea mayor que los gastos.

De igual manera, las cooperativas registran los inmuebles, mobiliarios $y$ equipos que poseen en el rubro de activo fijo, el monto del registro es por el efectivo pagado en ese momento. Ninguna de las cooperativas encuestadas, capitaliza los costos incidentales de los activos, generalmente se rigen por el monto pagado según la factura, a pesar de que las normas contables que las rigen establecen que se registre, como un costo, el monto pagado o factura; de igual manera deben ser manejadas todas las erogaciones realizadas en las compras o construcciones del bien para que esté en condiciones de ser utilizado. 
Para establecer el costo inicial del elemento de propiedades, planta y equipo, las cooperativas deben aplicar los principios contables al registrar los costos incidentales. Para tal fin, deben evaluar la adquisición del elemento del rubro para integrar en la medición inicial el monto pagado más los costos incidentales identificados y poner así el activo en condiciones normales de uso y todos los gastos incurridos para lograr la transferencia del bien. Las cooperativas no realizan estas evaluaciones. Se debería cambiar el nombre del rubro de Activo fijo por el de Propiedades, planta y equipo en los estados financieros que emiten las cooperativas. A continuación se esboza lo afirmado por las cooperativas 12 de octubre y Covadeca en relación al registro contable en el rubro Propiedades, planta y equipo.

C12 de Octubre: No le capitalizamos gastos a propiedades planta $y$ equipo.

CCovadeca: En propiedades, planta y equipo poseemos mobiliarios, equipos $y$ programas de computación.

En cuanto a la medición inicial de activos intangibles, sólo dos de las cooperativas seleccionadas poseen intangibles. La Cooperativa Cohello aspira registrar una marca que no esté en el mercado, y disfrutar las ventajas que ofrece el Estado. A pesar de que la gran mayoría de las cooperativas no presentan erogaciones en activos intangibles, tienen presente que son bienes que representan derechos y tienen valor jurídico o económico como medios para la realización de las operaciones normales. Explic an, que existen intangibles amortizables y no amortizables. Este sector de cooperativas, para darle mayor arraigo a su identidad, debe de tratar de crear una patente de invención y registrarla contablemente y cumplir el procedimiento establecido para intangibles generados internamente, o adquirir una marca exclusiva como indica la cooperativa Cohello, y registrarla como adquisición separada. Las cooperativas del sector deben de propiciar la creación de intangibles para arraigar su identidad o incorporar en sus operaciones los intangibles adquiridos en forma separada. La cooperativa de Servicios Generales Francisco Diez afirma:

CSGFD: Tenemos como activos intangibles un programa de computación.

Según información obtenida de las cooperativas seleccionadas, ellas no clasifican ninguna erogación en la categoría de otros activos. Exponen que en este rubro se contabiliza cualquier erogación no definida dentro de las demás agrupaciones. En este caso, son muy cuidadosas para no registrar contablemente este tipo de activo, generalmente se acogen al código establecido para registrar los pagos efectuados. La normativa prevé algunas partidas como: Fondos especiales para pensiones, jubilaciones y conceptos similares, activos fijos que estén fuera de uso y destinados a la venta, depósitos dados en garantía, efectos por cobrar en litigio. Un ejemplo es la cooperativa Mario Briceño Iragory.

CMBI: No manejamos otros activos. Nosotros somos una Cooperativa de Servicios Múltiples que podemos hacer cualquier cosa pero no estamos ubicados en eso ahorita.

Ninguna de las cooperativas del estudio presenta registros en este rubro, cargos diferidos, prefieren contabilizar a gastos toda la erogación. Un cargo diferido es un costo que se ha pagado en el presente, pero que 
se extenderá durante un largo período. Los cargos diferidos, tienen un marco de tiempo de transacción que excede de un año durante el cual se amortiza a través de cargos graduales. La cooperativa Covadeca certifica lo descrito anteriormente.

CCovadeca: No tenemos cargos diferidos.

Los cargos diferidos están identificados en las normas de SUNACOOP en el rubro 1.5. Son gastos causados y pagados por la cooperativa, cuyo beneficio económico abarca más de un ejercicio económico. Se deben amortizar durante el período en que se reciben los servicios o se causen los costos o gastos. La amortización implica un cargo a la cuenta de gastos. Establece SUNACOOP que los cargos diferidos serán amortizados en varios períodos, debitando a la cuenta de gastos de amortización y disminuyendo la cuenta del activo respectivo. La característica principal de este concepto es la expresión de obtener beneficios en futuros períodos económicos. Si un costo o gasto pagado anticipadamente permite a la entidad obtener un beneficio económico en el futuro, se está en presencia de un cargo diferido.

Con relación a la medición inicial de los pre-pagados, las cooperativas seleccionadas no los realizan, según los códigos de las entrevistas: 4-9,5-12,6-10,8-10,9-18,10-11 se destaca lo expuesto por la Cooperativa Cotiza, código 4-9. Indican que cuando se contabilizan valores pagados por anticipado se convierten en gastos a medida que se va consumiendo el servicio en el siguiente período contable. Exponen que son gastos que se registran como activo y deben ser utilizados dentro de un ciclo financiero a corto plazo. Los gastos pagados por anticipado, son costos que la cooperativa paga antes de que los costos realmente incurran. 


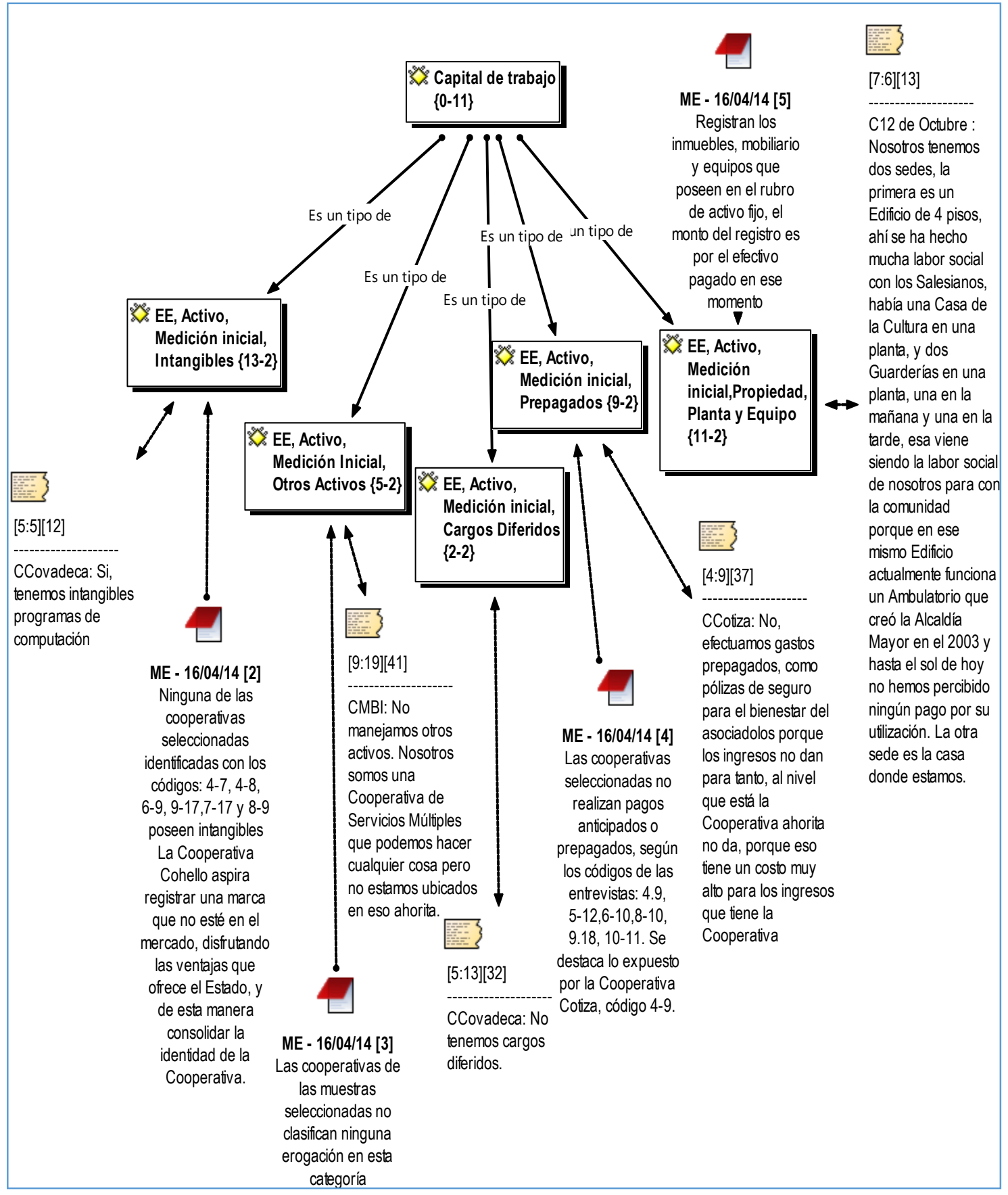

Gráfico 2. Red de la medición inicial del capital de trabajo de la EE. 
En el ciclo de la medición inicial que genera la inclusión de los activos al proceso productivo en las cooperativas de ahorro y crédito, los recursos financieros aportados por los asociados se recogen en el capital de trabajo, mediante la adquisición de bienes para ser incorporados al proceso productivo, que en el caso de las cooperativas de ahorro y crédito son los servicios financieros que prestan a los asociados, esta incorporación da lugar a las cuentas por cobrar, que una vez canceladas, las cooperativas obtienen la disponibilidad para comprar inversiones o realizables.

Las cooperativas de ahorro y crédito son consideradas organizaciones de gran importancia en la localidad, ofrecen servicios financieros a sus asociados, captan recursos de los mismos mediante afiliaciones de los individuos al pagar su cuota de ingreso y aportaciones asignadas; con estos recursos la cooperativa otorga el financiamiento a sus asociados cobrando una tasa de interés.

La captación de recursos permite a la cooperativa su autofinanciamiento. No dependen de recursos externos para desarrollar su actividad económica.

\section{CONCLUSIONES}

En la descripción de los componentes de la estructura económica de las cooperativas de ahorro y crédito inscritas en CECODIFEMI se determinaron las siguientes situaciones:

Las cooperativas en el reconocimiento del elemento de la estructura económicafinanciera no evalúan si la partida cumple la definición de elemento. Determinan la medición inicial de los elementos en función del monto pagado en efectivo o de la factura. El reconocimiento de la partida lo realizan según las especificaciones de la factura registrándolo en activo, pasivo, costos, gastos según la estructura del código contable.
Por otra parte, las cooperativas no cuentan con un marco conceptual que les indique los conceptos relacionados con la preparación y presentación de los estados financieros para usuarios externos. Los diferentes conceptos son abordados en tópicos específicos, pero no como un marco teórico.

El financiamiento que otorgan a los asociados lo registran en las cuentas por cobrar consideradas de riesgo mínimo en su cobrabilidad, debido a que el préstamo otorgado está en función de los haberes que posee el cooperativista o asociado. La disponibilidad en efectivo, es depositada únicamente en cuentas corrientes de los bancos nacionales. No utilizan una herramienta informativa que les permita evaluar las necesidades de efectivo en un momento determinado.

Las cooperativas están facultadas por la LEAC para invertir en instrumentos financieros, pero las de ahorro y crédito, de esta investigación, no lo realizan por desconocer las ventajas que representan y los riesgos que asumen. El rubro inversiones en inmuebles para la fecha de las entrevistas mostraba la cuenta sin ningún movimiento contable. Las cooperativas desvirtúan la naturaleza del concepto de inversiones en inmuebles lo asimilan al de propiedades, planta y equipo a pesar de que son elementos no incorporados al proceso productivo. Es así como uno de los casos estudiados, presenta en el rubro de Activo Fijo el monto correspondiente al inmueble otorgado en alquiler $y$ el ingreso que perciben por este concepto lo registran como "Provisión Reserva Inmueble".

En cuanto a valoración, las cooperativas únicamente utilizan los cálculos de la depreciación acumulada para evaluar los activos fijos, la amortización acumulada para los activos intangibles y el cálculo de la 
provisión para cuentas incobrables. No efectúan valoraciones en el resto de los activos señalados como capital de trabajo porque no efectúan erogaciones clasificadas en estos rubros. En forma general, la valoración de la estructura económica en estas cooperativas, es el valor en libros de los elementos de Propiedades, planta y equipo, activos intangibles y cuentas por cobrar.

\section{REFERENCIAS}

Bastidas, O. (2003). El cooperativismo en Venezuela. Red Universitaria de las Américas en Estudios Cooperativos y Asociativismo (UNIRCOOP) [Documento en línea]. Disponible en www.neticoop.org.uy documentos y desarrollo cooperativo. [Consulta, 2012, noviembre 10]

Bastidas, O. (2004). La Especificidad Cooperativa. Aportes a un cooperativismo Alternativo. Caracas: Cepac-UCV.

Bastidas, O. (2004). Panorama del Cooperativismo de Ahorro y Crédito (Papel de trabajo). Caracas: Centro de Estudios de Participación, la Autogestión y el Cooperativismo (Cepac) Universidad Central de Venezuela.

Catacora Carpio, F. (1999). PCGA en Venezuela: Comentarios y análisis de todas las Declaraciones de Principios de Contabilidad vigentes en Venezuela. Caracas: Fondo Editorial del Contador Público Venezolano.
Coopecas (2008) "Historia del cooperativismo". El Blog de Coopecas. Venezuela. En: http://asesoria.obolog.com/historiacooperativismo-167104

Fernández, E., Junquera B., y Del Brío J. (2009). Iniciación a los negocios: Aspectos Directivos [Libro en línea]. Ediciones Paraninfo S.A., Disponible: books.google.co.ve. [Consulta: 2012, abril 28].

Fernández García, R. (2009). Responsabilidad social corporativa. España: Editorial Club Universitario.

Fernández Pirla, J. (1977). Teoría Económica de la contabilidad: Introducción contable al estudio de la Economía, Madrid, España: Ediciones ICE.

Ley Especial de Asociaciones Cooperativas. LEAC (2001). Editorial Coprotel. Venezuela.

Sandoval, N. (2013). "Características de las empresas cooperativas". Página del Departamento de Cooperativas. Chile: Gobierno de Chile. Ministerio de Capacitación, economía y turismo, Unidad de Capacitación, Estudios y Difusión.

Valero, A. Á., y León, F. (2009). Debilidades de la globalización y el papel de la responsabilidad social empresarial. Economía, (27), 87-119.

Ley 1.178 del 20 de julio de 1990, La Paz, Bolivia

Sistema de Administración de Bienes y Servicios (2009). La Paz: Contraloría General de la República

Sistema de Administración de Personal (2003). La Paz: D.S. 26115 